\title{
RELIEVE MATERIALISTA DE HUGO WAST
}

16

A aparición de Hugo Wast en la literatura argentina coincide con los primeros signos del industrialismo, y por ende, las primeras concentraciones urbanas de importancia en el país. En la evolución social-económica de la república platense pueden distinguirse, al amparo de una generalización didáctica, tres grados importantes. El primero, agrario, agropecuario por decir mejor, de lucha entre la organización institucional y el caudillaje. La vida argentina se desenvuelve, principalmente, en el campo. Es la época de preeminencia para los latifundistas y los generales. La literatura que le corresponde, salvo excepciones más o menos gruesas, es una literatura gauchesca, extra-urbana, a veces influída por la pasión o el ideal político. Amalia de José Mármol, el Facundo de Domingo F. Sarmiento y el agudísimo Martín Fierro de José Hernández, son obras características de tal período.

Vencida la primera etapa, los inmigrantes, que arriban a millares, inician la transformación económica del país. La máquina y el industrialismo, aunque incipientes, provocan el crecimiento de los núcleos urbanos, en especial el de Buenos Aires, convertido muy pronto en gran ciudad. La vida social-económica transporta su eje. Comienza la hegemonía intelectual de la urbe y el tramonto del campo, reducido a un papel negativo y sumiso. Se opera la conjunción política en la capital federal. El caudillo, el generalote, tienden a desaparecer. La literatura también desplaza su eje. Se instala en las ciudades al cambiar el marco, la índole y la esencia de sus personajes. La vida de relación impone un ritmo nuevo a la creación artística, a pesar de esporádicos arrebatos individualistas. Se implantan los almacenes generales, se tienden tranvías eléctricos, corren ferrocarriles suburbanos. Todo ello ofrenda un gran público, brevemente ocioso y lector, chato y mediocre, característico de toda urbe naciente. El alma aldeana se retoca, pero s6́lo por fuera subsiste cierto primitiviśmo estético. La industrialización no es lo suficientemente poderosa como para brindar un nuevo tipo de hombre de gran ciudad. El pueblo, genéricamente, es un sufrido consumidor que compra todo a las industrias nacientes. Se produce, entonces, el auge de la compañía I acroze, de la sociedad Gath y Chaves y de Hugo Wast.

En adelante, toda excursión literaria más allá del suburbio estará impregnada de ideología urbanística. Don Segundo Sombra 
puede ser una excepción. Pero don Segundo Sombra no es una novela actual. En ella no figura ningún ferrocarril. Sus gauchos son gauchos de una época pretérita, cuando los aranceles norteamericanos y las maniobras de la Casa Bunge y Born no impedían formar un ambiente patriarcal, y hasta familiar y justiciero. En cambio, Fior de Durazno, de Hugo Wast, pese a su ubicación campesina, no es sino un común hecho de barrio, la seducción de una púber ingenua, arrancado a la letra truculenta de los primeros tangos y aderezado con una salsa romántico-sentimental, resabio del medioevo americano.

El tercer grado surge con la reciente intensificación industrial. Casi podría afirmarse que es típico de Buenos Aires. La gran condensación humana, el frote constante del hombre con el hombre, su aparición a la vida en un ambiente progresivamente refinado, desalojan los antiguos valores pasionales. El ímpetu bravío que vino del campo, y que el arrabal disfrazó en pasiones sensuales y dramas de bajo fondo, llega al centro urbano amansado y quieto. Triunfa el cine sobre el circo, el tango sobre la chacarera y el foot-ball sobre la doma de potros. Aparecen, entonces, los humoristas. El humorismo es un signo de madurez mental y no puede corresponder a una etapa feudal, o de artesanado. El brote de los humoristas argentinos, tan fresco y al mismo tiempo tan violento, es un signo más de la transformación del país.

$$
*^{*} *
$$

Desde luego el señor Wast no es un humorista, aunque haga humorismo sin saberlo. El señor Wast pertenece íntegramente al período de la transformación. Por eso en su obra se confunden, se balancean y chocan las dos tendencias opuestas: la agraria y la industrial.

El mismo es un caso de tal maridación. Es un hombre fecundo, de una bíblica y campesina fecundidad. Su prontuario novelístico es extenuante y aterrador. Además, cumple su papel de multiplicador de la especie con un empuje verdaderamente agrícola. Dicho sea con todo respeto, pero el crítico no puede olvidar que el señor Wast es padre de once criaturas y de catorce novelas. Esta es la faceta medioeval y primitiva del señor Wast, en una época donde triunfan el matrimonio sin hijos y la especialización científica. Pero Hugo Wast no ha desdeñado las enseñanzas del siglo capitalista. Y sus novelas son una especie de racionalización o taylorización de la literatura. El es una verdadera fábrica novelística, incansable y veloz, perfec- 
tamente conocedora del mercado de consumo y de las difíciles habilidades de la propaganda. El señor Wast, la máquina de escribir y la lectora del subterráneo han operado una confluencia histórica.

Pero no sólo su acción personal se resiente de la posición intermedia que ocupa Hugo Wast. También su ideología se encuentra matizada de presiones opuestas. Por una parte suele acudir a cierto realismo sensacionalista, muy de ciudad grande y Crítica 5. ${ }^{\text {. }}$ Pero por otra mantiene su vinculación con la Iglesia Católica. Aquí reaparece el hombre del feudalismo, católico, apostólico y romano, convicto y confeso. Todos sus libros cuidan muy bien no herir las conveniencias y enseñanzas de la Iglesia. Al contrario, suelen contener su defensa o su exaltación. De pronto el señor Wast suele prorrumpir en arrebatos místicos, en arengas catolizantes, como un nuevo cruzado que luchara heroicamente contra la triste corrupción del siglo. Es cierto que esta aptitud o filiación romanística le asegura la incansable propaganda del clero. Es cierto que las obesas madres católicas recomiendan a sus niñas cloróticas la lectura del novelista creyente. Pero sería una malignidad pensar que el señor Wast es católico por interés. Hijo de un ambiente familiar casi teológico, educado en colegios oleados y sacramentados, el señor Wast puede ser católico por convicción. Lo otro, apenas será una rienda que ate para siempre todo impulso apóstata o heterodoxo.

El señor Wast y su vasta familia viven exclusivamente de los libros. Esto es algo excepcional en nuestro continente. Señala un extraordinario éxito del autor, que le ha valido la envidia de todos los anónimos fracasados. Pero señala, también, una esclavitud con el gran público y sus mediocres aptitudes, que origina la crítica de las minorías renovadoras. Obligado a satisfacer la demanda creciente de niñas que sólo aspiran a leer libros rosados y tranquilos, el novelista de los almacenes generales y los tranvías suburbanos produce obras mansas, lechosas, rebosantes de sentimentalismo meloso, llenas de buenos ejemplos y rasgos conmovedores. El señor Wast no es para el público que sufre y ama las cosas grandes y hermôsas. Es un autor para la burguesía tranquila y rolliza, que quiere apartar de sí el espectro del desasosiego social. El señor Wast cumple su cometido puntualmente. Año tras año ofrenda sus obras aterciopeladas, donde hay niñas que hacen su primera comunión, novios que besan en las manos, hijas que se arrepienten, y donde flota, en un telón de fondo, el aura sacrosanta de un catolicismo triunfador. Las primeras concentraciones urbanas 
han creado esta demanda. Por una razón económica ineludible, Hugo Wast no puede renunciar a su industria. $Y$, por el contrario, la acelera y perfecciona.

Pese a todos los remiendos catolizantes. los triviales argumentos del señor Wast están teñidos de un urbanismo de la época capitalista, aunque jamás aborde las consecuencias sociales de las situaciones que plantea. Acude a ellas sólo para dramatizar la acción, enredar al lector y llevarlo preso en las mallas de la trama, pero sin detenerlo en una reflexión, sin abrirle los surcos fecundos de la duda o la inquietud.

Unicamente satisface Hugo Wast como paisajista. $Y$ es que, además de novelista, el señor Wast es pintor. Sus paisajes son sin alma, puramente objetivos. Pero no puede negársele una singular condición para describirlos sin cansar al lector.

Convendría referirse, aunque fuera someramente, a las principales novelas del fecundo autor. Pero ellas han dado vuelta a América en hombros de la vulgaridad. Flor de Durazno ha sido el libro de viaje de toda la burguesía argentina en tren de turismo. El drama de la campesina engañada que toca la puerta de las casas ricas para trabajar como sirvienta, ha producido innúmeros sollozos. Fara el señor Wast y para sus lectorcillas perfumadas no puede existir cosa peor que esa: pedir trabajo material. El episodio final, cuando el abuelo campesino niega a la abuela aristocrática la venta o posesión de la nieta, constituye una solución católica donde, además, se adula ingeniosamente el corazón y poder de la gran burguesía nacional.

Con Desierio de Piedra el señor Wast obtuvo los treinta mil pesos del premio nacional de literatura. Alguien llamó a esta obra el Desierto Literario. Se trata de otro argumento vacilante entre el tango y el cinematógrafo, incoloro e insípido, y que, sin embargo, devoraron con fruición los mansos lectores de Hugo Wast.

Sería ocioso referirse a libros como Casa de los Cuervos, Espigas de Ruth y otros que tuvimos el buen gusto de no leer. Sollo cabe escoltar este relieve recordando su última obra: Quince días de sacristán. El señor Wast relata en ella, con humilde prolijidad, la forma en que acompañó a Monseñor D'Andrea, gran Pontífice de la Iglesia argentina, en un hipodrómico paseo por Europa. El galope de ambos personajes por las tradicionales ciudades europeas se encuentra deliciosamente descrito. Catolizantes y ortodoxos, obispo y autor visitaron entre otros 
focos de la intelectualidad europea, la Abadía donde mora la hermana de una santa de última moda: Teresita de Francia. Los coloquios están fielmente transcritos. El lector se conmueve y transporta. Entornando los párpados se diría que es el medioevo que retorna al conjuro de la palabra sedosa del señor Wast.

Pero abrimos los ojos y vemos una Argentina nueva. Fábricas enormes, con un proletariado numeroso, conventillos hirvientes, donde una humanidad joven está forjando otro espíritu. Escuchamos la voz demoledora de los humoristas. Hugo Wast y su época, se van haciendo sombra, eco, humo, nada. Mujeres alegres y fuertes, desprejuiciadas y comprensivas, se ríen del autor de las novelas acarameladas y melifluas. Hasta su apellido ha entrado en decadencia. Ya no se dice Zuviría. Ahora se dice "Zuvitiola». El, entre tanto, sigue envuelto en sus inciensos. El novelista de los almacenes generales ya no trasciende a Houbigant. Apenas a sahumerio. La Iglesia lo arrastra hacia un altar.-M A N UEL A. SEOANE.

Exclusivo para Alenea en Chile.

\section{AL MARGEN DE UN LIBRO REGIENTE}

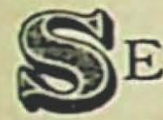

dice con frecuencia que el escritor no ocupa la digna posición que a su categoría corresponde, ni ejerce la acción social que de él reclaman, con singular urgencia, las circuntancias de la hora presente. Realmente no existe en Chile una clase intelectual. Sólo se cuentan entre nosotros los elementos que podrían servir de extremidades a su constitución orgánica: el investigador y el creador, aislados entre sí. Y mientras aquél censura a éste por su falta de precisión, su intrascendencia, el literato reprocha al erudito su acartonamiento y la carencia de espíritu de selección. Con respecto a estas apreciaciones, bien pudiéramos hacer notar que la menor o mayor importancia de un historiador es percibida generalmente por la mayoría, teniendo en cuenta las dimensiones de su documentación, mientras que la valorización de un literato sólo puede ser apreciada por una élite. En todo caso falta un tercer elemento destinado a servir de nexo entre estos extremos, para la formación de una clase intelectual. Y ese término medio, llamado a fijar rumbos definitivos. en medio de las estridencias de creadores e investigadores que se combaten, no puede ser compuesto por una fracción de literatos, en gracia de su indocumenta- 